\title{
URUGUAY 2007: El COMPLEJO AÑO DE LAS REFORMAS
}

\author{
Uruguay 2007: The Complex Year of the Reforms
}

\section{DANIEL CHASQUETTI}

Universidad la República-Uruguay

\begin{abstract}
RESUMEN
El artículo analiza el año político uruguayo a partir de dos tendencias contrapuestas. Por un lado, los éxitos inocultables del gobierno de izquierda en el terreno económico y social y, por otro, el descenso en la popularidad del gobierno en la opinión pública. La explicación que guía el trabajo se relaciona con el alto costo político que tuvo la aprobación de las reformas estructurales impulsadas por el presidente Vázquez. De este modo, el artículo pasa revista al trámite de la reforma tributaria, la reforma de la salud, la reforma del Estado y la reforma de la educación. También se analizan los cambios introducidos en el gabinete, la labor del Parlamento y el acontecer de los partidos políticos.
\end{abstract}

Palabras clave: Gobierno, Presidente, Reformas.

\begin{abstract}
The article analyzes the Uruguayan political year from two opposing tendencies. On the one hand, the successes of the government in the economic and social areas and on the other hand, the fall of the positive opinion in public opinion surveys. This paradox has its origin in the high political cost that the approval of the structural reforms had in the legislative branch. For this reason, the article reviews the process of creation and approval of the tax reform, the health reform, the state reform, and the education reform. Finally, the article reviews the changes introduced in the cabinet by the president, the yearly work of the Parliament, and the situation of the Uruguayan political parties..
\end{abstract}

Key words: Government, President, Reforms.

\section{EL GOBIERNO DE VÁZQUEZ EN SU TERCER AÑO}

El año 2007 fue un buen año para el Uruguay. El PBI creció un 7,4\% -por quinto año consecutivo-, la inflación se mantuvo controlada pese a que superó levemente las metas anunciadas por el gobierno $(8,5 \%)$, las exportaciones de bienes y servicios alcanzaron los U\$S 7.000 millones (un 35\% más respecto a 2006), el ingreso promedio de los hogares aumentó un 9,4\%, el desempleo cayó al 8,2\%, y la proporción de hogares en situación de pobreza e indigencia continuó decreciendo en consistencia con la tendencia registrada en los últimos dos años. Sin embargo, esta evolución no se tradujo en un aumento de popularidad del gobierno, ni tampoco en un respaldo masivo al partido gobernante. ${ }^{1}$

1 Sobre fin de año, dos encuestas de opinión pública mostraron que la intención de voto del Frente Amplio cayó. Factum registró en diciembre una caída de tres puntos porcentuales ( $47 \%$ al $44 \%$ ), en tanto Interconsult registró en noviembre una pérdida de dos puntos (41\% al 39\%) Por más información, ver [En línea] 
Por el contrario, el gobierno atravesó un año difícil, signado por la aprobación de complejas reformas estructurales en el Parlamento y por la intensa competencia en la interna del partido de gobierno a partir de la negativa del presidente de impulsar una reforma constitucional que posibilitara su reelección. La evolución de la popularidad del presidente muestra claramente estos hechos. Entre diciembre de 2006 y agosto de 2007, la aprobación de la gestión presidencial registró una caída de diez puntos porcentuales, lo cual es lo mismo que decir que el gobierno perdió en ese lapso la quinta parte de sus apoyos. Los meses posteriores registraron un leve repunte pero la sensación de haber sorteado un año difícil pautado por el costo de las reformas resulta inocultable. Desde luego que en todo esto influyó la crítica desplegada por la oposición que, a diferencia de lo ocurrido en el pasado año, logró ahora sí construir un discurso verosímil centrado en el rechazo a las reformas del gobierno. ${ }^{2}$

\section{Gráfico 1: Aprobación de la Gestión del Presidente Vázquez, Año 2007}

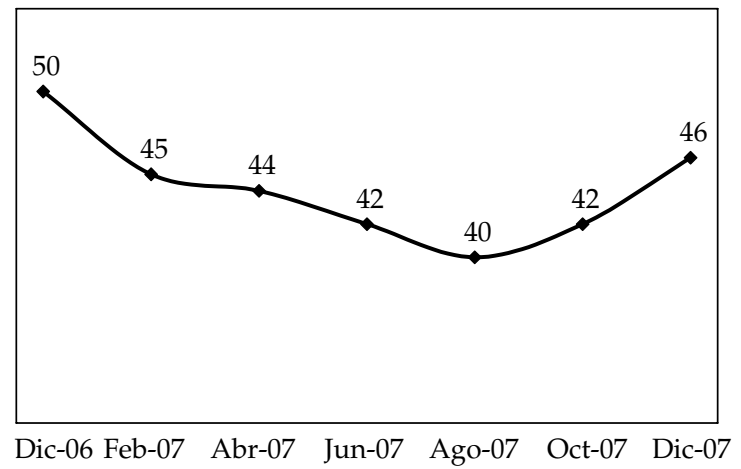

Fuente: Equipo Mori.

\section{El año de las reformas}

A fines de marzo de 2007, durante una reunión de su Consejo de Ministros, el Presidente Vázquez presentó las seis prioridades para el año: Reforma Tributaria, Reforma de la Salud,

<http:/ / www.espectador.com.uy/1v4_contenido.php?id=112145> y http:/ / www.ultimasnoticias.com.uy/ hemeroteca/261107/prints/act05.html [Consulta: 03:01:2008]

2 Si bien es cierto que la caída de la aprobación presidencial coincide con la tramitación de las reformas y la ofensiva de la oposición, no debe descartarse la influencia del fuerte impulso inflacionario que experimentó el país durante el trimestre julio-septiembre. Este fenómeno obligó al equipo económico a implementar un paquete de medidas para detener la presión inflacionaria. El aumento de productos básicos como las frutas y verduras (a causa de un fenómeno estacional) o la carne y los lácteos (a causa del aumento de precios internacionales), seguramente contribuyó al descenso de la popularidad del gobierno durante ese breve período. El caso uruguayo ha sido bien estudiado por Andrés Rius (1992), quien demostró la existencia de una significativa asociación entre la performance económica (en particular la evolución del nivel de inflación) y la aprobación de la gestión presidencial. Años más tarde, Luna (2002) confirmó este hallazgo para la serie histórica 1985-1999, y demostró que, bajo ciertas condiciones, la polarización política también puede ser una variable de impacto negativo sobre la evaluación presidencial. 
Reforma del Estado, Plan de Equidad, Plan Ceibal, ${ }^{3}$ y desarrollo del Uruguay Productivo. Si bien estas metas políticas guiaron el desempeño del gobierno, otros issues políticos ingresaron en la agenda e incidieron decisivamente en el acontecer político uruguayo. Asuntos como el anuncio presidencial de no intentar reformar la Constitución para alcanzar la reelección para un nuevo período, el debate sobre la inserción internacional del país, los brotes inflacionarios de los meses de julio y agosto y los procesamientos de militares vinculados a la dictadura militar influyeron en la marcha de los acontecimientos.

El programa de gobierno del Frente Amplio ubicaba a las reformas del sistema impositivo, el sistema de salud y el Estado como las medidas de gobierno más importantes a impulsar. Si bien en el discurso presidencial de asunción se anunció que las reformas serían tramitadas a la brevedad, el gobierno tardó entre uno y dos años para dar forma técnica y política a los proyectos de ley.

Un primer borrador del proyecto de reforma tributaria fue presentado públicamente en diciembre de 2005. Tres meses más tarde el mismo ingresó al Parlamento con la idea de alcanzar una rápida aprobación. Sin embargo, pese a las mayorías legislativas del partido de gobierno, la reforma tardó siete meses en sortear las observaciones de la Comisión de Hacienda de la Cámara de Diputados. Luego de complicadas negociaciones los legisladores oficialistas acordaron con el Ministerio de Economía una serie de modificaciones que dieron paso a su aprobación sobre finales de 2006. De este modo, la reforma tributaria entró en vigencia recién el $1^{\circ}$ de julio de 2007 y según sus artífices, pretendió "favorecer una mayor equidad entre los contribuyentes, transformando al sistema impositivo en un estímulo para la inversión productiva y el empleo". ${ }^{4}$ La reforma eliminó quince impuestos, gravó las rentas de empresas y sociedades comerciales, estableció estímulos para la reinversión y determinó un sistema dual de aportes basado en el impuesto a la renta del capital y el trabajo. Los partidos de la oposición fustigaron duramente estos cambios, por entenderlos recesivos para la economía e injustos para el contribuyente. Este discurso, centrado en la idea de que la reforma golpeaba a la clase media ganó a un importante segmento de la población, lo cual se vio rápidamente confirmado en las encuestas de opinión pública. ${ }^{5}$

La reforma de la salud sufrió un trámite bastante similar. Su tramitación insumió un largo tiempo debido a la necesidad de construir un consenso entre los sectores del partido de gobierno. Los principales lineamientos de la reforma de la salud se dieron a conocer a mediados de 2005 cuando el Ministerio de Salud Pública presentó un borrador de reforma

3 El Plan Ceibal es un programa orientado a entregar una computadora portátil a cada escolar de la enseñanza pública. El ente encargado de la educación primaria (ANEP) realizó un acuerdo con la empresa estatal de comunicaciones (ANTEL) a los efectos de garantizar la cobertura tecnológica en todo el país, de forma que los niños pudiesen acceder a bibliotecas virtuales, juegos y proyectos pedagógicos. El financiamiento de este plan fue aprobado en la Rendición de Cuentas 2006 con el apoyo de todos los partidos y comenzó a ser ejecutado en el mes de noviembre de 2007.

4 Según el Presidente, "el Uruguay Productivo, no es una expresión de deseo, sino una estrategia de país orientada al desarrollo". Al respecto ver [En línea] <www.mef.gub.uy/reforma_tributaria.php> [Consulta: 28:12:2007].

5 Una encuesta de la empresa Cifra \& Raga Asociados del 12 de septiembre, señalaba que casi la mitad de los uruguayos (49\%) estaba en contra de la reforma tributaria y, en particular, del impuesto a la renta de las personas físicas. El apoyo a la reforma alcanzaba sólo el 29\%. [En línea] http://www.cifra.com.uy/noticias. php> [Consulta: 27:12:2007]. 
que generó duras críticas de la oposición y ambiguas reacciones entre las fracciones del partido de gobierno. En virtud de las críticas, el gobierno inició un rediseño de la reforma a los efectos de darle sustento político y técnico. Un grupo integrado por técnicos de los Ministerios de Economía y de Salud Pública trabajó durante varios meses en la confección de tres proyectos de ley que compondrían la reforma. En agosto de 2006, fue presentado en el Parlamento el primer proyecto de Descentralización de la Administración de Servicios de Salud del Estado. Dos meses más tarde, fue presentado el proyecto de Creación del Fondo Nacional de Salud (FONASA) compuesto por aportes de trabajadores, empleadores y el Estado. Estos dos proyectos se aprobaron en los meses de mayo y julio de 2007, con el voto de todos los partidos. ${ }^{6}$ Por último, en febrero de 2007, el Ejecutivo envió el tercer proyecto que establece la Creación del Sistema Integrado de Salud. Su aprobación, a comienzos de diciembre de 2007, estuvo precedida por un arduo debate en torno a la centralidad estatal en el sistema, el grado de discrecionalidad que se otorga al Ministerio de Salud Pública y el papel que se reserva a las mutualistas médicas, principales prestadoras privadas de atención del país. La reforma de la salud, por tanto, se transformó en otro centro de disputa entre el gobierno y la oposición, al tiempo que dejó en claro los costos internos de transacción que tiene el gobierno de Vázquez. El rediseño de la reforma supuso una transacción técnica y, al mismo tiempo, un acuerdo político entre el equipo económico y el de salud pública.

La Reforma del Estado fue la tercera gran iniciativa del gobierno en 2007. Ya a fines de de 2006, Vázquez había presentado esta iniciativa como la "madre de todas las reformas" y para su tramitación creó una comisión interministerial encargada de implementar las principales líneas de acción. No obstante, este procedimiento se mostró poco eficiente, por lo cual, en marzo de 2007, el presidente tomó la drástica decisión de realizar cambios en la dirección política de la reforma. Designó al senador Enrique Rubio -líder de la Vertiente Artiguista, una de las principales fracciones del Frente Amplio- como Director de la Oficina de Planeamiento y Presupuesto (OPP, dependencia con rango ministerial) y radicó en ella el objetivo de diseñar e impulsar la Reforma del Estado.

La Reforma del Estado del Frente Amplio apunta a redimensionar el Estado en función de los objetivos estratégicos definidos por el gobierno. Para ello inició una reestructura de los niveles gerenciales del Estado, una redefinición de las competencias de los funcionarios públicos, y particularmente, la formulación de una política de recursos humanos fundada en la meritocracia. La propuesta también alienta la participación ciudadana y la descentralización de los recursos públicos mediante una serie de cambios institucionales y la incorporación de tecnología a la gestión estatal. En 2007, la OPP concentró su trabajo en la reestructura de las carreras funcionariales y en el diseño de las agencias descentralizadas del interior del país (denominadas "ventanilla única"). La Ley de Rendición de Cuentas 2006 -ley de carácter presupuestal sancionada este año-incorporó numerosos artículos orientados a la facilitación de ese proceso. Por otra parte, en el mes de julio de 2007, el Director de OPP dio a conocer un anteproyecto de ley de descentralización política y administrativa del país que establece la creación de autoridades locales electas en más de cien centros 
urbanos, y el desarrollo del denominado "gobierno electrónico". ${ }^{7}$ A diferencia de las otras grandes iniciativas del gobierno de Vázquez, la Reforma del Estado no generó grandes controversias con la oposición, aunque sí desató conflictos crecientes con los sindicatos de funcionarios estatales, compuestos por una gran mayoría de votantes del gobierno. ${ }^{8}$

Otra reforma importante -aunque de menor entidad que las anteriores tres- es la sustitución del Plan de Atención Nacional a la Emergencia Social-PANES, programa de emergencia dirigido a la población en situación de pobreza e indigencia- por el denominado Plan de Equidad. Este cambio supone la transformación de una política de emergencia que tenía un horizonte temporal de dos años, por una política social estable y permanente. ${ }^{9}$ A diferencia del PANES, el Plan de Equidad no prevé un "ingreso ciudadano" para las personas indigentes, pues opta por canalizar las transferencias hacia los beneficiarios a través del sistema institucionalizado de "Asignaciones Familiares" (se paga un monto determinado por niño que concurra al sistema educativo formal). Con tal objetivo, el Ejecutivo incorporó en la Rendición de Cuentas 2006 un rubro presupuestal de 65 millones de dólares, que fue aprobado por los legisladores del gobierno y rechazado por los partidos de oposición. Pese a ello, esta reforma parece ser la menos controvertida de las impulsadas en el presente año, debido a que el mecanismo escogido se ajusta a los formatos institucionales históricos del estado de bienestar uruguayo y porque, como lo reconocen todos los actores, los niveles de pobreza son todavía altos.

Finalmente, debe mencionarse la reforma más trabada y lenta del gobierno de Vázquez, la Reforma de la Enseñanza. En 2006, el gobierno desarrolló un amplio debate sobre sus contenidos con la participación de los actores implicados que culminó con la realización del Congreso de la Educación. Las conclusiones de este evento serían tomadas en cuenta para la redacción del proyecto de ley de reforma, sin embargo, como el Congreso estuvo dominado por los sindicatos de la educación y sus resoluciones tenían un tono radical y estatista, el gobierno encontró grandes dificultades para avanzar en una propuesta concreta. Durante el transcurso de 2007 se esperaba la presentación del proyecto de ley en el Parlamento pero el mismo nunca fue terminado en virtud de las controversias desatadas en el seno del partido de gobierno. En el mes de octubre trascendieron algunas de las ideas que serían incluidas en el proyecto de reforma, ${ }^{10}$ lo cual de por sí desató una fuerte reacción de los sindicatos -que consideraban que las mismas no contemplaban las resoluciones del

7 Iniciativas de esta naturaleza fueron impulsadas en las últimos tres lustros en países de la región y el mundo (ver Pollitt y Bouckaert (2000), Peters (2000), Serna de la Garza (1998). Incluso en Uruguay, los primeros emprendimientos datan de 1987, cuando el gobierno colorado del Presidente Julio María Sanguinetti impulsó la "modernización del Estado". Desde entonces, cada gobierno, a partir de su visión sobre el rol que el Estado debe cumplir en la sociedad y la economía, promovieron ajustes estructurales de mayor o menor envergadura.

8 Al respecto, en un seminario organizado por el Círculo de Montevideo, el Vicepresidente de la República sostuvo que "hay funcionarios que han privatizado las empresas públicas en su propio beneficio".

9 El Banco Mundial valoró positivamente la experiencia del PANES, al valorar que este programa tuvo un impacto positivo en la reducción de la población indigente en Uruguay. Al respecto, ver [En línea] <http:/ / www.presidencia.gub.uy/_Web/noticias/2007/11/2007112909.htm> [Consulta: DIA28:MES12:2007AÑO].

10 Según los trascendidos, la reforma incorporaría formas de participación a nivel de los centros de educación como mecanismo de mejora de la calidad del servicio y la rendición de cuentas. Los sindicatos, en cambio, aspiran a la participación institucional en el nivel de conducción nacional de la enseñanza, lo cual podría ser considerado una suerte de cogobierno. 
Congreso-y de los partidos de la oposición -que entendían que esas medidas vulneraban la tradición de laicidad de la educación uruguaya-. Al iniciarse 2008, el dilema para el gobierno sigue vigente y no está claro si insistirá con la idea de reformar la educación o si, por el contrario, dejará esta empresa para un eventual segundo mandato.

En suma, todas las reformas tuvieron un trámite difícil para el gobierno. Primero acordar a la interna del partido, soportando la presión de los grupos de la sociedad afines a la izquierda, y luego negociar o absorber las críticas de la oposición. En el centro Vázquez y sus principales ministros argumentando acerca de la necesidad de los cambios. La ciudadanía no siempre comprendió.

\section{El debate en torno a la reelección presidencial}

Dado que la Constitución uruguaya impide la reelección inmediata del presidente, la especulación acerca de quién será el sucesor de Vázquez ha ido creciendo con el paso del tiempo. Pese a su caída, las encuestas continúan señalando al Frente Amplio como el favorito para ganar la próxima elección, por lo cual la definición de su candidato presidencial no es un asunto menor. ${ }^{11}$ La mayoría de los analistas consideran al ministro de Economía, Danilo Astori, como uno de los probables precandidatos, dado los éxitos de su política económica y su excelente imagen entre el público de centro. Otro aspirante es el ministro de Ganadería y Agricultura, José Mujica, cuya popularidad supera a la de cualquier integrante de este gobierno, incluida la del propio Presidente. Los otros nombres manejados son los del Vicepresidente de la República, Rodolfo Nin Novoa, y el del Director de la OPP, Enrique Rubio. No obstante, como ninguno de los cuatro concita el consenso de todos los sectores del Frente Amplio, algunos dirigentes comenzaron a especular el pasado año con la posibilidad de reformar la Constitución para que Vázquez pueda postularse a un segundo mandato presidencial.

Una enmienda de esta naturaleza exige o bien la aprobación de una ley constitucional que cuente con el apoyo de $2 / 3$ de cada cámara, o bien, la presentación de un proyecto de reforma que cuente con la firma de los 2/5 de la Asamblea General (reunión de ambas cámaras) y que posteriormente sea plebiscitado en forma conjunta con la siguiente elección nacional. El primer camino de reforma es inviable para los promotores de la reelección debido al nítido rechazo de los partidos tradicionales a habilitar este mecanismo. La segunda vía obligaría al Frente Amplio a transitar un camino sinuoso ya recorrido por el ex Presidente colorado Jorge Pacheco Areco en 1971. En esa oportunidad, Pacheco -un presidente de derecha que coartó las libertades civiles- intentó aprobar sin éxito la reelección y el naciente Frente Amplio se opuso enfáticamente aludiendo que la enmienda contribuiría a perpetrar en el poder al presidente. La sola posibilidad de que Vázquez fuera comparado con Pacheco por intentar modificar la Constitución de la misma forma,

11 Por ejemplo, la encuesta realizada por la empresa Factum en el mes de septiembre de 2007 mostraba al Frente Amplio con una intención de voto del 47\%, seguido por el Partido Nacional con 31\%, el Partido Colorado con el 9\% y el Partido Independiente con el 1\%. Ver [En http://www.factum.com.uy/> [Consulta: DIA29:MES12:AÑO2007]. 
desalentó el entusiasmo de sus precursores, principalmente el del propio presidente. ${ }^{12}$ Hay alguna evidencia desde las encuestas de opinión sobre el apoyo a esta reforma. Probablemente, esto influyó en la decisión del Presidente.

Fue así que el 4 de junio Vázquez anunció en cadena de televisión que no intentaría reformar la Constitución para buscar la reelección. Esta decisión generó importantes consecuencias sobre el partido de gobierno, pues dejó en claro que la candidatura del Frente Amplio se resolvería en las internas de junio de 2009. Desde entonces, el partido de gobierno comenzó a verse agitado por las aspiraciones de algunos de sus precandidatos y sobre todo de los sectores que pretenden cerrarle el paso a alguno de ellos. Tal vez el hecho más emblemático de este fenómeno fue la tramitación de la Rendición de Cuentas 2006 y la discusión en torno al presupuesto para la enseñanza, donde se enfrentaron los partidarios del ministro de Economía con los sectores que aspiran a imponer a otro $\mathrm{u}$ otros candidatos. ${ }^{13}$

Pero la decisión de Vázquez generó también un impacto positivo sobre la oposición. Al día siguiente del anuncio, los senadores Jorge Larrañaga (Presidente del Directorio del Partido Nacional) y Julio María Sanguinetti (Secretario General del Partido Colorado) se reunieron para intercambiar opiniones y concluir en que la decisión del presidente devolvía a los partidos tradicionales la chance de triunfo: "sin Vázquez el Frente Amplio no podrá alcanzar un triunfo en primera vuelta". ${ }^{14}$ Este encuentro de los líderes de los partidos de oposición dejó en evidencia el respeto que ambos profesan por el presidente, como así también su temor ante el potencial electoral de Vázquez. El propio presidente había adelantado la satisfacción de los líderes de la oposición cuando expresó en su discurso una llamativa premonición: "Cierro los ojos y me parece ver algunos rostros exhalando un profundo suspiro de alivio". ${ }^{15}$

\section{La inserción internacional en debate}

Al igual que en 2006, la política internacional del país estuvo dominada por el interminable conflicto con Argentina y por el recurrente debate acerca de la inserción internacional del país. El conflicto entre Uruguay y Argentina había cerrado el 2006 de la peor manera (ver Anuario 2006). Mientras los ambientalistas argentinos cortaban el puente internacional Gral. San Martín, ${ }^{16}$ el gobierno de Kirchner conseguía que el Rey de España se involucrara

12 No obstante, las encuestas de opinión pública dejaban ver que existía buena predisposición en la ciudadanía a considerar una reforma de esta naturaleza. Por ejemplo, una encuesta de Grupo Radar, realizada en octubre de 2006, señalaba que "el 59\% de los uruguayos cree que en Uruguay debería existir la reelección presidencial" [En http://www.gruporadar.com.uy/opinion_2006.htm. [Consulta: 10:03:2008].

13 La disputa se centró en torno a una partida de 30 millones de dólares para la educación que el equipo económico se negaba a incluir en el mensaje complementario del Ejecutivo. La salida encontrada consistió en recortar el nivel de inversiones del sector público. Los grupos del Frente Amplio que promovían la mejora presupuestal interpretaron el resultado de la negociación como una victoria sobre Danilo Astori. Ver La República, 28-06-07. Ver en http:/ / www.larepublica.com.uy> [Consulta: DIA28:MES12:2007AÑO].

14 Semanario Búsqueda, 07-06-2007, página 5.

15 http://www.presidencia.gub.uy/_web/noticias/2007/06/2007060405.htm> [Consulta: DIA02:MES01:2008 AÑ].

16 El corte del puente se inició el 20 de diciembre de 2006 y permanece vigente hasta el momento en que se escribe este artículo. 
en el conflicto con el objetivo de acercar las partes con vistas a una negociación sobre el tema.

En 2007 el conflicto pareció entrar en un impasse ya que, salvo las mínimas novedades que aportaban las reuniones promovidas por el delegado del Rey, la situación se mantuvo sin modificaciones hasta finales de año. Los tímidos acuerdos alcanzados suponían el compromiso de los gobiernos de no exacerbar el conflicto con acciones que complicaran la gestión del monarca español. Por esa razón Uruguay pospuso dos veces la inauguración de la planta de celulosa (elecciones presidenciales argentinas y Cumbre Iberoamericana). La posibilidad de un entendimiento mínimo entre los gobiernos se abrió en vísperas de la Cumbre Iberoamericana de Jefes de Gobierno de Santiago de Chile. La idea era acordar un documento de carácter técnico que estableciera el monitoreo conjunto de los gobiernos sobre el funcionamiento de la planta. No obstante, la negociación fracasó por errores absurdos cometidos por ambos gobiernos. Primero los técnicos argentinos llegaron tarde a Santiago y sin instrucciones para negociar; luego el presidente argentino, Néstor Kirchner, brindó su apoyo a la causa de los ambientalistas frente a toda la prensa internacional; finalmente, el presidente uruguayo -en respuesta a las declaraciones de este último- ordenó telefónicamente a su ministro de Medio Ambiente la firma del decreto que habilitaba a iniciar sus trabajos a la planta de celulosa. Esta cadena de errores provocó un malestar inocultable en ambas delegaciones y generó el disgusto del Rey de España. Las tres partes dieron por terminadas las gestiones y el conflicto volvió a foja cero. Desde entonces, todo continúa igual salvo que la planta de la empresa finlandesa Botnia está produciendo y que las dudas respecto al nivel de contaminación que pueda generar, serán develadas a la brevedad. Mientras tanto, el puente que une ambos países sigue cortado y los gobiernos mantienen una fría relación en espera del fallo final de la Corte Internacional.

El segundo tema dominante de la agenda se relaciona con este conflicto y con el estado crítico del MERCOSUR. Muchos analistas coinciden en que el programa de integración acordado en los años noventa entre los cuatro países del bloque se encuentra en punto muerto. La crisis desatada en la región a comienzos de la década condujo a los gobiernos de Argentina y Brasil a renegociar un entendimiento a comienzos de 2003 (conocido como acuerdo estratégico) que implica el desarrollo de medidas tendientes a favorecer a la economía argentina, y a reequilibrar la balanza comercial entre ambos países mediante mecanismos arancelarios. El desarrollo de estas medidas bilaterales provocó un fuerte malestar en los gobiernos de Uruguay y Paraguay, que pugnaban por reestablecer las metas de la unión aduanera y poner en marcha un programa que atemperara las fuertes asimetrías de la región. La no intromisión de Brasil en el conflicto entre Argentina y Uruguay cayó muy mal en Montevideo, generando una sensación de indefensión nunca antes percibida.

Desde entonces, el gobierno del Frente Amplio debió de realizar grandes esfuerzos para mantener un discurso en defensa del MERCOSUR. En sus discursos, Vázquez pasó de su ya clásica consigna "más y mejor MERCOSUR" al concepto del "MERCOSUR como plataforma hacia el mundo", lo cual supone, según sus portavoces, permanecer en el bloque pero logrando acuerdos comerciales bilaterales con otras economías del mundo. Ya el 
anterior presidente, Jorge Batlle, había llegado a una conclusión idéntica cuando negoció un Tratado de Libre Comercio con México (desatando una fuerte polémica en el seno del MERCOSUR) y Tratados de Protección de Inversiones con Estados Unidos y Finlandia. El gobierno del Frente Amplio parece encaminarse por el mismo camino y por ello Vázquez visitó este año once países (Chile, Emiratos Árabes, Estados Unidos, Ecuador, Qatar, Bélgica, España y Portugal, Nueva Zelanda, Malasia y Vietnam), al tiempo que recibió la importante visita del Presidente de EE.UU., George Bush. En todos sus viajes, Vázquez procuró abrir mercados para los productos uruguayos y captar inversiones para ciertas áreas estratégicas de la economía nacional. En la casi totalidad de los viajes estuvo acompañado por el ministro de Economía -favorable a aumentar el comercio extra zona-, prescindiendo de la presencia del ministro de Relaciones Exteriores, Reinaldo Gargano, principal defensor del MERCOSUR. La oposición, por su parte, no pasó por alto las diferencias dentro del gobierno ni tampoco la lenta modificación de la estrategia de inserción internacional. En su opinión, el gobierno desarrolla una política internacional incoherente y carente de sustento a mediano plazo.

En suma, el gobierno de Vázquez continúa tensionado por dos estrategias diferentes: por un lado, la de mantener la lealtad a los gobiernos de izquierda de la región -cuyo puntal es el ministro de Relaciones Exteriores junto a una parte del partido de gobierno y al movimiento sindical-; por otro, la de desarrollar una amplia relación comercial con el mundo -cuyo puntal es el ministro de Economía junto a una parte menor del partido de gobierno y al conjunto de partidos de la oposición-. Por el momento, no existen señales que permitan creer que este dilema será resuelto a la brevedad. Por el contrario, resulta muy probable que Vázquez culmine su mandato manteniendo en pie ambas visiones y que transfiera la resolución del problema al próximo presidente.

\section{Otro dictador a prisión}

Uno de los hechos más destacados del año fue sin duda el procesamiento del ex dictador, Gregorio Álvarez, en diciembre de 2007, por la desaparición y muerte de dos militantes de izquierda durante los años de dictadura militar. El conocido "Goyo" Álvarez fue uno de los principales impulsores del golpe de Estado de 1973, condujo los terribles operativos de represión del período 1975-1980 y fue presidente de facto durante el período final de la dictadura (1981-1985). Su detención se suma a la de otros símbolos de la dictadura, como el ex Presidente y mentor del golpe, Juan María Bordaberry, su Canciller, Juan Carlos Blanco, y los militares y policías integrantes de la tristemente célebre OCOA, organización creada en los años setenta para desarticular y reprimir a los principales grupos políticos de izquierda.

Algunos analistas opinan que estos éxitos sólo fueron posibles gracias al arribo al gobierno del Frente Amplio. Otros creen que este ha sido un lento proceso vivido por el país donde los temas vinculados a la violación de los derechos humanos durante la dictadura comenzaron a ser revalorizados de otra forma por las nuevas generaciones. Una y otra interpretación conviven hoy en día, pese a que resulta muy cierto que fue el gobierno del Frente Amplio el que abrió el cauce para que los dictadores y su séquito fueran encarcelados. No sabemos 
si estos hechos representan un punto final, al menos simbólico, sobre el tema, pues existe evidencia que conduce a pensar que el tema permanecerá en la agenda pública por muchos años más. En los tribunales se acumulan demandas contra militares retirados, las organizaciones de derechos humanos continúan activas, los sindicatos juntan firmas para colocar en la Constitución una enmienda que anule la Ley de Caducidad (de amnistía a los militares votada por los partidos tradicionales en 1986), etc.

\section{PODER EJECUTIVO}

\section{Cambios en el gabinete}

El gobierno de Vázquez cuenta con una mayoría legislativa en las cámaras que le permite aprobar leyes, sostener ministros ante llamados a sala del Parlamento y designar a voluntad autoridades de los Entes Públicos. Por esta razón, la cohesión del partido de gobierno en el Legislativo resulta crucial para la gobernabilidad, particularmente si se repara en el alto nivel de fraccionalización interna que el Frente Amplio muestra. Cuando el presidente asumió, construyó un centro de decisión política en el gabinete, al nombrar como ministros a la casi totalidad de los líderes de las fracciones del partido gobernante. Aunque esta integración facilitó la línea de mando y generó equilibrios en la interna del gobierno, mostró al mismo tiempo cierta rigidez para incorporar modificaciones.

En marzo de 2007 Vázquez realizó el primer relevo de importancia al sustituir al ministro del Interior, José Díaz, por la diputada socialista Daisy Tourné. ${ }^{17}$ Más allá de que el ministro saliente (también de filiación socialista y dirigente de confianza personal del presidente) adujo razones personales, se trató de un cambio necesario en una cartera que ofrecía problemas serios para el gobierno. La sustituta responde a una corriente del Partido Socialista que disiente con la línea impuesta por el líder histórico del sector, el ministro de Relaciones Exteriores, Reinaldo Gargano. Poco tiempo después, en mayo, el presidente relevó al Director de la Oficina de Planeamiento y Presupuesto (OPP), Carlos Viera, y designó al senador de la Vertiente Artiguista, Enrique Rubio. Si bien muchos analistas interpretaron esta modificación como una señal hacia los sectores más izquierdistas del gobierno, ${ }^{18}$ el cambio estuvo asociado al relanzamiento de la reforma del Estado y a la inclusión en el gabinete de un liderazgo en ascenso. Si bien el máximo exponente de dicho sector, el ex intendente de Montevideo, Mariano Arana, integra el gabinete desde el inicio del gobierno, parece bastante claro que en estos años Rubio se fue transformando en el líder indiscutible de la Vertiente Artiguista. ${ }^{19}$

17 La trayectoria política de Daisy Touné se inició en el sindicato de maestros en los años previos a la recuperación de la democracia. En 1999 ingresó a la cámara baja, y en la elección de 2004 encabezó la lista de diputados del Partido Socialista por Montevideo.

18 Durante los dos primeros años del gobierno de Vázquez, el senador Rubio realizó importantes críticas a la conducción del ministro de Economía, Danilo Astori. En agosto de 2005, cuando se trataba el presupuesto quinquenal en el Parlamento, su sector impulsó enmiendas que provocaron la renuncia de Astori. Esa situación crítica fue saldada por la intervención directa del presidente y del ministro de Ganadería, José Mujica, evitando así la salida del Ministro.

19 En la elección legislativa nacional, la lista al senado de la Vertiente Artiguista fue encabezada por Mariano Arana. Enrique Rubio aparecía en segundo lugar. 
Por tanto, los cambios en el gabinete obedecieron hasta ahora a dos lógicas diferentes y complementarias. Vázquez buscó fortalecer al gobierno en áreas políticas donde existían problemas, pero al mismo tiempo procuró reforzar el poder del gabinete, en la perspectiva de que éste continúe siendo un centro de decisión. Con estos cambios, Vázquez bajó en más de un año el promedio de edad del gabinete (64,8 años) y elevó a cuatro el número de mujeres ministras, lo cual es un récord para un país donde hasta 2004 sólo habían existido tres casos de mujeres al frente de ministerios. ${ }^{20}$

Tabla 1: Gabinete de ministros del presidente Vázquez. 2007

\begin{tabular}{lccc}
\hline Ministerio & Ministro & Fracción & Edad \\
\hline Defensa Nacional & Azucena Berrutti & Partido Socialista & 77 \\
Desarrollo Social & Marina Arismendi & Partido Comunista & 57 \\
Economía y Finanzas & Danilo Astori & Asamblea Uruguay & 66 \\
Educación y Cultura & Jorge Brovetto & Independiente & 73 \\
Ganadería, Agricultura y Pesca & José Mujica & MPP & 70 \\
Industria, Energía y Minería & Jorge Lepra & Independiente & 64 \\
Interior & Daisy Tourné & Partido Socialista & 56 \\
Relaciones Exteriores & Reinaldo Gargano & Partido Socialista & 72 \\
Salud Pública & María Julia Muñoz & Independiente & 57 \\
Trabajo y Seguridad Social & Eduardo Bonomi & MPP & 57 \\
Transporte y Obras Públicas & Víctor Rossi & Alianza Progresista & 63 \\
Turismo y Deporte & Héctor Lescano & Alianza Progresista & 58 \\
Vivienda, Ord. Territorial y M. Ambiente & Mariano Arana & Vertiente Artiguista & 73 \\
Oficina de Planeamiento y Presupuesto & Enrique Rubio & Vertiente Artiguista & 64 \\
\hline
\end{tabular}

Fuente: Elaboración propia.

\section{Funcionamiento del gabinete}

Al igual que lo ocurrido en años anteriores, el gabinete de Vázquez se reunió en 2007 casi semanalmente. También realizó sesiones abiertas en pequeñas localidades del interior del país, con el objetivo de "acercar el gobierno a la gente" (como le gusta decir al presidente). Muy similar a lo que quiso Bachelet con el "gobierno ciudadano". No obstante, ese funcionamiento colectivo convivió con el hecho innegable de que ciertos ministros controlan importantes cuotas de poder que les permiten imponerse a sus pares. En particular, el ministro de Economía contó en estos últimos dos años con la capacidad de controlar ciertas políticas ajenas a su cartera en virtud de que las mismas implicaban modificaciones estructurales

20 Durante algunos meses de 1967, Alba Roballo estuvo al frente del Ministerio de Instrucción Pública; entre 1985 y 1989, Adela Reta fue ministra de Educación y Cultura, y entre 1995 y 2000, Ana Lía Pieñeyrúa fue ministra de Trabajo y Seguridad Social. 
vinculadas al sistema impositivo o a la formulación del gasto (reforma de la salud, reforma del estado, transformación del PANES en Plan de Equidad, etc.).

Otro hecho importante, ha sido la transformación de la Secretaría de Presidencia en un centro de poder encargado de la gestión de asuntos complejos, como la negociación del conflicto con Argentina o la negociación comercial con los Estados Unidos en el marco del TIFA. El titular de esta Secretaría, el Dr. Gonzalo Fernández (la mano de derecha del presidente como se afirma en la prensa), coordinó con frecuencia estrategias con los ministros implicados (Economía, Relaciones Exteriores), pero también tomó sus propias decisiones bajo el amparo y respaldo del presidente. Por esta razón, puede afirmarse que Vázquez ha construido un delicado sistema de toma de decisiones donde convive un gabinete con un importante funcionamiento colectivo junto a mecanismos de by-pass que le permiten dar coherencia al accionar del gobierno y afrontar situaciones inesperadas o riesgosas con relativa eficiencia.

\section{PODER LEGISLATIVO}

\section{Integración y funcionamiento del Parlamento}

Como se afirmó antes, el Frente Amplio domina el Legislativo con el 53\% de los escaños en la Cámara de Diputados y el 55\% del Senado. El Partido Nacional es el principal partido de la oposición y cuenta con el peso legislativo como para llamar a sala a los ministros por su sola voluntad (más de un tercio de alguna de las dos Cámaras). El Partido Colorado es el tercer partido en importancia pero su peso legislativo específico apenas sobrepasa el 10\% de las bancas. El Partido Independiente cuenta con un único diputado y carece de representación en el Senado (ver Tabla 2).

Tabla 2: Integración del Poder Legislativo 2005-2010

\begin{tabular}{lrrrr}
\hline & \multicolumn{2}{c}{ Diputados } & \multicolumn{2}{c}{ Senadores } \\
\hline Frente Amplio & 52 & $53 \%$ & 17 & $55 \%$ \\
Partido Nacional & 36 & $36 \%$ & 11 & $35 \%$ \\
Partido Colorado & 10 & $10 \%$ & 3 & $10 \%$ \\
Partido Independiente & 1 & $1 \%$ & 0 & $0 \%$ \\
TOTAL & 99 & $100 \%$ & 31 & $100 \%$ \\
\hline
\end{tabular}

Fuente: Chasquetti (2007).

Desde un punto de vista formal, el Parlamento uruguayo es un organismo bicameral, cuyas cámaras difieren muy poco en sus funciones. La diferencia crucial la hacen los partidos políticos, pues su organización tiende a colocar en el Senado a los líderes de las fracciones y en Diputados, en líneas generales, a la representación local de los partidos. En esta legislatura el partido de gobierno cooptó a sus líderes para el gabinete, pero la 
oposición mantiene a sus principales figuras en la Cámara (Jorge Larrañaga, Luis Alberto Heber y Gustavo Gallinal en el Partido Nacional y Julio María Sanguinetti en el Partido Colorado).

El Vicepresidente de la República, Rodolfo Nin Novoa, líder de la fracción Alianza Progresista, ejerce la Presidencia de la Asamblea General (reunión de las dos cámaras) y la Presidencia del Senado. Su función principal es la de coordinador del trabajo entre las dos ramas del gobierno. A la interna del Legislativo su principal tarea es la de organizar el trabajo parlamentario actuando como un verdadero gatekeeper que distribuye los proyectos del Ejecutivo entre las cámaras. Como contrapartida, la Presidencia de la Cámara de Diputados es un cargo pro-témpore (se elige cada año) y normalmente su designación, al igual que las tres vicepresidencias, responde a un acuerdo celebrado por todos los partidos al iniciarse la legislatura. En los años impares del actual período, la Presidencia la ejerce un diputado frenteamplista, y en los años pares un diputado nacionalista.

Cada Cámara cuenta con 16 comisiones permanentes, pudiéndose nombrar comisiones especiales e investigadoras para analizar temas que el cuerpo considere relevantes. Las presidencias y vicepresidencias de las comisiones son elegidas al comienzo de cada año y también responden a un acuerdo general celebrado por los partidos al inicio del mandato. Esta configuración determina un Parlamento débil desde un punto de vista institucional, y partidos extremadamente poderosos que controlan el flujo de las decisiones. Las carreras legislativas, entonces, se explican más por las decisiones de los partidos que por los cargos que ejercen los legisladores durante su trayectoria política.

\section{Producción parlamentaria}

Entre el $1^{\circ}$ de marzo de 2007 -fecha de inicio del año legislativo- y el 31 de octubre se presentaron en el Parlamento uruguayo 188 proyectos de ley y se sancionaron 85 leyes. El Poder Ejecutivo envió 79 proyectos de ley (42\%), los legisladores presentaron 108 (58\%), y la Suprema Corte de Justicia, 1. Un 71\% de las leyes sancionadas (60) fueron iniciadas por el Ejecutivo y sólo un 29\% (25) por los legisladores. Estos datos confirman el poder de agenda del Poder Ejecutivo uruguayo en el proceso legislativo, a partir de la combinación de factores políticos e institucionales que operan en ese sentido: una mayoría legislativa estable y disciplinada; prerrogativas constitucionales, que reservan al presidente la iniciativa exclusiva en áreas como el presupuesto, la creación de empleo público, impuestos y pensiones; y reglas internas del Parlamento que garantizan el control del proceso a la mayoría en funciones.

Entre las normas más destacadas del año se encuentran la aprobación del Régimen de promoción y defensa de la competencia, la Descentralización de los Servicios de Salud del Estado, la creación del Fondo Nacional de Salud (FONASA), la Creación del Sistema integrado de Salud, la Rendición de Cuentas del Ejercicio 2006, el Régimen de Derechos y Obligaciones de la Unión Concubinaria, el Régimen de Producción y Comercialización de los Agrocombustibles, la Ley de Reglamentación del Tránsito Vial. La totalidad de estas leyes fueron iniciadas por el Poder Ejecutivo y votadas por la unanimidad de legisladores del partido gobernante. 
Un capítulo aparte lo configuró el tratamiento del proyecto de Ley de Defensa de Derechos de la Salud Sexual y Reproductiva que, entre otras medidas, despenaliza el aborto en Uruguay. Este proyecto había sido presentado por la bancada del Frente Amplio en la anterior legislatura y a pesar de haber logrado la media sanción del Parlamento, naufragó tras las amenazas de veto anunciadas por el entonces Presidente, Jorge Batlle. En la actual legislatura sucedió algo parecido, pues los legisladores de izquierda volvieron a presentar el proyecto, pero el presidente Vázquez anunció que lo vetaría si el Parlamento lo aprueba. A pesar del anuncio presidencial, los legisladores del gobierno tramitaron el proyecto en el Senado, forzando una votación en el pleno en el mes de noviembre, donde los artículos referidos al aborto fueron rechazados. Los legisladores de la oposición junto a dos integrantes del Frente Amplio -que adujeron razones morales y políticas-conformaron una mayoría que bloqueó su pasaje. Sin embargo, un mes más tarde y tras arduas negociaciones, esos artículos fueron considerados y aprobados con una única deserción oficialista y el voto del senador colorado Julio María Sanguinetti. El proyecto ahora se encuentra en la cámara baja, y si bien sus promotores saben que Vázquez no dudará en vetarlo, están convencidos de llegar hasta esa instancia como forma de mantener el tema en la agenda. Obviamente, este proceso desató la movilización a favor de las organizaciones sociales y la drástica oposición de la Iglesia Católica. Una encuesta de opinión pública realizada en el mes de octubre mostró que un $67 \%$ de los uruguayos está a favor de despenalizar el aborto. ${ }^{21}$

Tabla 3: Producción legislativa 2005-2007

\begin{tabular}{lccccc}
\hline & \multicolumn{2}{c}{ Poder Ejecutivo } & \multicolumn{2}{c}{ Poder Legislativo } & Total \\
\hline Proyectos presentados en 2005-2006 & 287 & $37 \%$ & 479 & $63 \%$ & 766 \\
Proyectos presentados en 2007 & 79 & $42 \%$ & 109 & $58 \%$ & 188 \\
Total de proyectos & 366 & $38 \%$ & 588 & $62 \%$ & 954 \\
Leyes sancionadas en 2005-2006 & 158 & $66 \%$ & 80 & $34 \%$ & 238 \\
Leyes sancionadas en 2007 & 60 & $71 \%$ & 25 & $29 \%$ & 85 \\
Total de leyes sancionadas & 218 & $67 \%$ & 105 & $33 \%$ & 323 \\
Proyectos pendientes & 148 & $23 \%$ & 483 & $77 \%$ & 631 \\
Eficacia (leyes / proyectos) & $60 \%$ & & $18 \%$ & & $34 \%$ \\
\hline
\end{tabular}

Fuente: Informe de la actividad parlamentaria 2005-2007.

El proceso legislativo en Uruguay muestra entonces que el Ejecutivo cuenta con un importante poder de agenda y que la oposición queda relegada a un papel casi marginal en materia de iniciación de la legislación. No obstante, su papel crece cuando se considera la labor de las comisiones y, particularmente, el rol fiscalizador del Parlamento sobre la administración. Los datos disponibles muestran que el $28 \%$ de los proyectos presentados por el Ejecutivo y que finalmente se transforman en ley, durante el período 2005-2007, 
fueron modificados por las comisiones parlamentarias. Este guarismo es más del doble del observado en los períodos anteriores y obedece a dos fenómenos diferentes. Por un lado, la evidencia muestra que la bancada de gobierno realiza cambios a los contenidos enviados por el Ejecutivo y eso responde a la necesidad de establecer acuerdo en torno a los contenidos (aproximadamente la mitad de los cambios) y, por otro, la bancada de gobierno negocia cambios con la oposición con el objetivo de ampliar la base de respaldo de la ley.

Tabla 4: Leyes iniciadas por el Ejecutivo y modificadas por las comisiones parlamentarias

\begin{tabular}{lccc}
\hline Legislatura & Leyes & Modificadas & Porcentaje \\
\hline $1995-2000$ & 341 & 38 & $11 \%$ \\
$2000-2005$ & 399 & 56 & $14 \%$ \\
$2005-2007$ & 218 & 63 & $28 \%$ \\
\hline
\end{tabular}

Fuente: Informe de la actividad parlamentaria 2005-2007.

El sistema de fiscalización del Parlamento uruguayo sobre el Ejecutivo está formado por tres dispositivos institucionales: los pedidos de informes a los ministerios (acto individual de cualquier legislador); la comparecencia de los ministros en las comisiones del Parlamento (a pedido de las propias comisiones); los llamados a sala y eventual interpelación a los ministros (con un tercio de los votos de alguna de las cámaras). La oposición es quien normalmente despliega estos instrumentos que en la práctica representan un elemento distintivo de la rendición de cuentas horizontal de la democracia uruguaya. Como podrá observarse en la Tabla 5, cada año el Parlamento envía al Ejecutivo, en promedio, unos 500 pedidos de informe, de los cuales el $87 \%$ son iniciados por los partidos de oposición. Asimismo, los 28 jerarcas ministeriales (ministros y viceministros) concurren por año en promedio unas 4 veces a las comisiones parlamentarias. Finalmente, la oposición ha realizado en promedio casi 4 llamados a sala de ministros por año.

Tabla 5: Fiscalización del Parlamento 2005-2007

\begin{tabular}{lr}
\hline Pedidos de informes a los Ministerios & 1.541 \\
Comparecencias de ministros en comisión & 365 \\
Llamados a Sala e Interpelaciones de Ministros & 11 \\
\hline
\end{tabular}

Fuente: Informe de la actividad parlamentaria 2005-2007.

Desde luego, estos movimientos tienen consecuencias políticas importantes. Por ejemplo, el ministro del Interior saliente, durante sus dos años en funciones, fue llamado a sala en tres oportunidades, debió concurrir 14 veces a las comisiones y recibió 79 pedidos de informe. Si se comparan estas cifras con las de los ministros menos cuestionados por la 
oposición se puede constatar que los mecanismos de fiscalización son un buen indicador del conflicto entre el gobierno y la oposición.

\section{LOS PARTIDOS POLÍTICOS}

Los partidos políticos uruguayos son un factor determinante del funcionamiento de la democracia uruguaya. Durante el año 2007, los mismos se mostraron activos no sólo a nivel del Parlamento, sino también en lo que hace al despliegue de su vida orgánica. Las Convenciones $^{22}$ de los tres partidos de la oposición se reunieron en dos ocasiones en el año, en tanto en el mes de diciembre sesionó el Congreso del Frente Amplio. Los partidos tradicionales, a su vez, realizaron elecciones juveniles de diferente naturaleza pero con igual suceso. Una nota sobre el sistema electoral sería apropiado.

\section{Elecciones juveniles en los partidos tradicionales}

El 12 de mayo se realizó la elección de la Convención de Jóvenes del Partido Nacional, donde se presentaron 438 listas y más de 12 mil candidatos. ${ }^{23}$ Sus organizadores esperan una participación cercana a los 30 mil votantes, pero los resultados finales mostraron una votación de 52.483 sufragantes. En estos comicios podían votar jóvenes que tuvieran entre 14 y 29 años, sin necesidad de estar afiliados al partido. El resultado de la votación fue interpretado como un éxito por los analistas y la dirigencia del partido. Como sentencia de la jornada electoral, el presidente del Directorio nacionalista, el senador Jorge Larrañaga, dijo que esa colectividad "es el partido de los jóvenes".

A su vez, el $1^{\circ}$ de diciembre se realizó la elección de 100 jóvenes colorados que ingresarían como miembros permanentes a la Convención del partido. Para estas elecciones fueron inscriptas 430 listas en todo el país con unos 10 mil candidatos. También aquí podían votar jóvenes entre 14 y 29 años, sin necesidad de estar afiliados al partido. ${ }^{24}$ Sus organizadores esperaban una participación de unos 15 jóvenes, pero la votación final sobrepasó el cálculo de los más optimistas. Según fuentes partidarias, participaron 46.559 jóvenes.

Según la Constitución de 1996, la Convención es el máximo organismo de los partidos en Uruguay y está integrada por 500 convencionales elegidos en las elecciones internas simultáneas que se realizan en el mes de junio del año de la elección nacional. El Frente Amplio reúne su Convención sólo para cumplir requisitos formales, pues mantiene como máximo organismo a su Congreso de delegados de base y de sectores.

23 De acuerdo al Reglamento aprobado para la Elección Nacional de Jóvenes en octubre de 2006, el acto electoral elegiría un Congreso Nacional de 300 integrantes y Congresos Departamentales de jóvenes. El sistema electoral reproducía algunos aspectos del sistema electoral nacional. Se permitió el uso del doble voto simultáneo para que las listas de un mismo sublema pudiesen acumular votos, representación proporcional con fórmula d’Hont para asignar los cargos, y 19 circunscripciones departamentales con un número preestablecido de cargos. El padrón electoral se constituyó en el propio acto electoral, ya que los participantes se inscribían aportando datos básicos como el nombre, la fecha de nacimiento, la identificación civil y la firma. Esta práctica es similar a la utilizada por el Frente Amplio desde comienzo de los noventa para la elección de autoridades. Por más detalles, ver [En línea] [http://www.partidonacional.com.uy/cgi-bin/EleccionJuventud.asp]

24 El sistema electoral utilizado por los jóvenes colorados era bastante parecido al utilizado por sus congéneres nacionalistas. La diferencia estriba en que el Partido Colorado no eligió órganos juveniles sino que creó cien nuevos cargos en la Convención Nacional. 
Si bien los resultados de ambas contiendas son parecidos, existieron importantes diferencias que deben ser señaladas. En la elección de jóvenes del Partido Nacional la presencia de las fracciones nacionales no fue clara. Resultaba dificultoso determinar a qué sector pertenecía cada lista, y el resultado final no mostró el triunfo de ninguna fracción en particular. La elección colorada, en cambio, contó con una actuación más notoria de las fracciones, ya que los 100 cargos en juego podían afectar la correlación de fuerzas de la Convención. Los resultados finales indican esta apreciación: el "Foro Batllista" (fracción liderada por Julio María Sanguinetti) logró la mayor votación, seguida por "Vamos Uruguay" (fracción liderada por Pedro Bordaberry, hijo del dictador y ex ministro de Turismo de Jorge Batlle) y la "Lista 15" (fracción liderada por Jorge Batlle). No obstante, el resultado final para el Partido Colorado ha sido importante, pues devolvió el optimismo a los principales dirigentes, que luego de la magra votación obtenida en las elecciones nacionales y municipales, creían que pasaría un largo tiempo para que el partido pudiese ponerse en pie.

\section{El Congreso del Frente Amplio}

El V Congreso del Frente Amplio se realizó entre el 13 y 16 de diciembre de 2007 y llevaba el nombre de su ex presidente y fundador, General Liber Seregni, fallecido en julio de 2004. El evento estuvo presidido por una compleja discusión sobre cuál era el papel que debe jugar un partido de gobierno que se define de izquierda y que encuentra grandes dificultades para resolver el vínculo con sus integrantes en el gobierno. Pero a esto se agregó el planteo del ministro de Ganadería y líder del MPP, José Mujica, respecto a la necesidad de renovar la dirección partidaria, removiendo a su actual presidente y colocando al frente a la politóloga, Constanza Moreira, junto a una vicepresidencia colectiva integrada con representantes de las principales fracciones. Ante este planteo, el presidente en funciones y actual ministro de Educación, Jorge Brovetto, anunció que no aspiraría a la reelección en el cargo, mientras que el Partido Comunista propuso la creación de una presidencia colegiada integrada por representantes de las cinco fracciones mayores. A partir de entonces, el problema de la elección del presidente se transformó en el tema dominante del período preparatorio, sobre todo, cuando se supo que la elección de delegados de base otorgó un tercio de los congresales al MPP y otro tercio al Partido Comunista. De este modo, ambos sectores se configuraron en actores de veto para la elección del presidente, ya que el estatuto del Frente Amplio exige dos tercios de congresales para su designación (unos 1.330 delegados sobre 2.000 integrantes).

Las sesiones del Congreso estuvieron dominadas por una fuerte discusión en torno a la forma que adoptaría la presidencia, y en los talleres de discusión programática no se mostraron grandes avances. Una declaración muy negociada sobre la inserción internacional del país desechaba la idea de realizar un Tratado de Libre Comercio con Estados Unidos bajo el formato negociado por Colombia y Perú, y el apoyo a la campaña de recolección de firmas para la derogación de la ley de caducidad a través de una enmienda constitucional, fueron las únicas resoluciones alcanzadas. Como los desacuerdos fueron notorios en torno al tema de la presidencia partidaria, el Congreso resolvió entrar en cuarto intermedio hasta el mes de abril de 2008. La mayoría de los analistas interpretaron este resultado como un 
fracaso del partido de gobierno para mostrar una postura coherente ante la ciudadanía, abriendo dudas mayores respecto al futuro de este partido, sobre todo cuando el próximo congreso extraordinario de abril de 2009 deberá definir el programa que presentará en las elecciones de ese año y la candidatura presidencial que procurará suceder a Vázquez en el próximo período.

\section{EL GOBIERNO DE IZQUIERDA EN EL RECODO DEL PERÍODO}

El 2007 fue el tercer año de gobierno del Frente Amplio y estuvo marcado por dos tendencias contrapuestas. Por un lado, el gobierno continuó cosechando éxitos en materia económica y social. Los indicadores en esas materias muestran avances significativos que en general son reconocidos por dentro y fuera del país. Sin embargo, la popularidad del gobierno ha sufrido este año un importante deterioro en virtud de las reformas estructurales aprobadas. Las encuestas de opinión muestran este fenómeno y siembran tímidas dudas sobre la continuidad de la izquierda en el gobierno. Las reformas tributaria y de la salud no fueron bien recibidas por la clase media urbana, y las reformas del estado y la educación provocaron resistencias en los sindicatos estatales, históricas bases electorales de la izquierda uruguaya. En este proceso la oposición también ha realizado su juego, estructurando un discurso orientado a criticar las medidas más impopulares de la izquierda, y adoptando una postura mucho más mesurada, sobre todo a partir de la noticia de que el presidente no intentaría modificar la Constitución para correr por la reelección.

Este escenario dejaría en claro que las reformas estructurales tienen un costo y el gobierno lo está pagando con creces. Vázquez argumenta que cumplirá con su programa de gobierno y que los réditos de las reformas serán palpables con el transcurso del tiempo. La incertidumbre abierta por su definición de no ser reelecto parece haber atentado sobre la gestión del gobierno, pues la competencia entre los principales aspirantes a la sucesión comenzó a notarse más de lo debido. Vázquez sabe que el próximo año será aun peor y para eso ya prepara una recomposición del gabinete donde los principales precandidatos (Astori, Rubio, Mujica) quedarán en libertad de acción. La oposición también sufrirá del mismo mal, pues allí también habrá competencia y conflicto por la carrera presidencial, por lo cual es de esperar que la calma mostrada este año varíe por una actitud mucho más dura hacia el gobierno. El 2008 será entonces un año preelectoral donde la agenda pública cambiará el debate en torno a las policies por los temas típicos de toda carrera electoral.

\section{REFERENCIAS}

Chasquetti, Daniel (2007). “Uruguay 2006: éxitos y dilemas del gobierno de izquierda”, en Revista de Ciencia Política. Volumen especial, 27 (EE), pp. 249-263. Santiago de Chile: Universidad Católica.

Informe "El Parlamento uruguayo. Imagen pública y producción legislativa durante el período 2005-2007". Montevideo: Poder Legislativo-Instituto de Ciencia Política. 2008.

Luna, Juan Pablo (2002). “¿Pesimismo estructural o voto económico? Macropolitics en Uruguay", en Revista Uruguaya de Ciencia Política. N 13, pp. 123-151. Montevideo: ICP-EBO. 
Peters, Guy (2000). "De cambio en cambio: patrones de continuidad en la reforma administrativa", en Revista del CLAD Reforma y Democracia. N²4, octubre, pp. 1-14. Caracas.

Pollitt, Christopher. y Gert Bouckaert (2000). Public Management Reform: A Comparative Analysis. Oxford: Oxford University Press.

Rius, Andrés (1992). "El gobierno, la economía y el hombre de la calle", en Revista Suma 7, pp. 7-35. Montevideo: Universidad Católica.

Serna de la Garza, José María (1998). La reforma del Estado en América Latina: Los casos de Brasil, Argentina y México. Instituto de Investigaciones Jurídicas. Serie Estudios Jurídicos. Número 3.

Daniel Chasquetti es profesor de política comparada del Instituto de Ciencia Política de la Universidad de la República. Publicó en coautoría el libro "Fragmentación política y gobierno en Uruguay: ¿un enfermo imaginario?, y numerosos artículos en revistas nacionales e internacionales.

(E-mail: chasquetti@cpolit.edu.uy) 
